\title{
SPACE-TIME VARIATION OF ACCESSIBILITY TO JOBS BY PUBLIC TRANSPORT - A CASE STUDY OF SZCZECIN
}

\author{
Sławomir Goliszek \\ Institute Geography and Spatial Organization \\ Polish Academy of Sciences \\ Twarda 51/55, 00-818 Warsaw: Poland \\ sgoliszek@twarda.pan.pl
}

\begin{abstract}
The article includes an analysis of spatial and temporal possibilities of commuting to work by collective transport during the morning rush hours in Szczecin. This article focuses on transport accessibility by collective transport in Szczecin measured with the use of Geographic Information System (GIS) tools and General Transit Feed Specification (GTFS) format for exchanging public transportation schedule and geographic information. A public transport model includes journey sources who are people of working age and destinations which are different workplaces in Szczecin. The main objective of the article to determine places of the highest accessibility by collective transport within 1-minute period of time. The accessibility analysis for jobs and companies is made in Szczecin, as Szczecin's public transport operator has published the GTFS format as the first in Poland. In addition, Szczecin has a very specific urban layout, separated by a river and connected by one (main communication artery) and the other smaller bridge for crossings between Lewobrzeżem and Prawobrzeżem. The analysis is to show the exact hour during which the largest number of citizens has the possibility to commute to the highest possible workplaces. The result shall depict interdependence between various components (space usage, time, individual), transport accessibility and a choice of a place having the best possible accessibility during the morning rush hours (Geurs \& Ritseman van Eck 2001). The results are to be presented with the use of the cumulative accessibility and graphs. ${ }^{1}$.
\end{abstract}

Key words: commuting to work, public transport, isochrones, transportation components.

\section{Introduction}

The researchers who focused on commuting to work were Hamiltion (1982) and White (1988). A still-growing number of studies and publications concerning this subject has emerged since they published their works. Most of them regards spatial distribution of journey sources and destinations (Cropper \& Gordon 1991; Giuliano \& Small 1993; Kim 1995; Manning 2003; O'Kelly \& Lee 2005;

\footnotetext{
1 The article has been written on the basis of research project "Potential accessibility of regions and their development potential in a "united" Europe - spatial coverage, length of travel and the border effect (EU-ROAD-ACC)". The project has been financed from the National Science Centre UMO-2014/13/B/HS4/03397.
} 
Niedzielski 2006; Charron 2007; Yang 2008; O’Kelly \& Niedzielski 2009; Murphy 2009; Loo \& Chow 2011; Boussauw et al. 2011; Chowdhury et al. 2013).

Reduction in journey times in cities is essential from a social, economic and environmental point of view (Givoni \& Banister 2013). Reducing traffic congestion while commuting to work, i.e. lowering the number of cars, results in a decrease in greenhouse gas emission (Małecki et al. 2014). It can be achieved in a number of ways, e.g. by shortening the distance between the source (place of residence) and the destination (workplace). Another ways involve using means of public transport or a car which is $80 \%$ full (Åkerman \& Höjer 2006; Modarres 2013).

Providing access to public transport to the highest possible number of citizens is considered a real challenge for transport policies introduced in cities and regions. Most of citizens of a city having a public transportation system shall have the possibility to commute to work or school in an economically acceptable way (Lau 2011; Lucas 2011; Naudé 2008; Yongling \& Guonan 2009). Another essential issue is attractiveness of a given job what can be expressed by the salary, additional benefits provided by the company and economical effectiveness of commuting (Cervero 2001). Journey time and cost is important for both an employee and an employer. Employees who spend lots of time commuting to and from work may be generally dissatisfied and this may lead to a decrease in economic efficiency of their work (Novaco \& Gonzalez 2009).

In order to increase the effectiveness of transport policies and improve commuting possibilities it is essential to obtain reliable transport data allowing to measure everyday traffic and all contributing factors. The issue of commuting to and from work is usually studied in the highly developed countries while in developing ones it is not that usual (Punpuing 1993; Shirgaokar 2014). The developing countries often lack data on commuters and their features, e.g. age, gender, occupation or places of residence (Aguilera 2005; Shearmur 2006). Moreover, the network data is often hardly accessible yet its accessibility has improved during the last few years. It started to change when General Transit Feed Specification data has become available (Poelman \& Dijkstra 2015).

GTFS format was created in the United States of America (USA) in the early 90s of the twentieth century. Initially, the patronage of the introduction of the format of the data was coordinated by Google. Currently the tools to use GTFS data can be found in ESRI's ArcGIS. This format of data of coding public transport is currently used by most boards of public transport companies in the US and in Western and Central Europe. Hence research on public transport in these areas is measured with high precision (Widener et al. 2015; Farber et al. 2014). GTFS data format was also used for comparisons of public transport systems and modeling travel characteristics based on the selected mean of transportation or lack of it (Poelman \& Dijkstra 2015). A large part of the studies using GTFS is utilized to compare public and individual transport (Salonen \& Toivonen 2013; Wang et al. 2015). Comparison of individual and public transport can lead to conclusions on their functioning and how to promote intelligent transport systems in urban areas (Malecki et al. 2014; Tao et al. 2014). The creation of data format General Transit Feed Specification (GTFS) and their implementation by authorities responsible for public transport in the city created new possibilities for the analysis of transport. GTFS data format is more often used to model the transport accessibility (rail, tram, trolley, bus, aircraft, and automobile; Hadas 2013; Fransen et al. 2015).

The GTFS is a data standard which is used to describe the public transport system and it contains the public transport stops (including their geographical location), routes and schedules. By using data GTFS it enables one to investigate real-time accessibility by public transport, it is attracting growing attention from practitioners and the scientific community. It is used to evaluate the efficiency of the 
public transport network in general (Hadas 2013), providing practical conclusions that enhance the effectiveness of public transport systems (Tao et al. 2014). In addition, GTFS data enables a more precise assessment to be made of the level of socio-spatial disparities in the metropolitan area (El-Geneidy et al. 2015; El-Geneidy et al. 2016). The precise information on the public transport schedules permits a better understanding of temporal changes of accessibility patterns (Farber et al. 2014; Fransen et al. 2015; Stępniak \& Goliszek 2017).

All social phenomena and transport are linked. Every time when people are making decisions about travel is connected directly with the component transport accessibility (Geurs \& van Wee 2004). The phenomenon of commuting to work measured with the cumulative accessibility measure may be presented in a diagram (Geurs \& van Wee 2004; Geurs \& Ritseman van Eck 2001) showing relationships between various components of transport accessibility which determine accessibility of workplaces (Fig. 1).

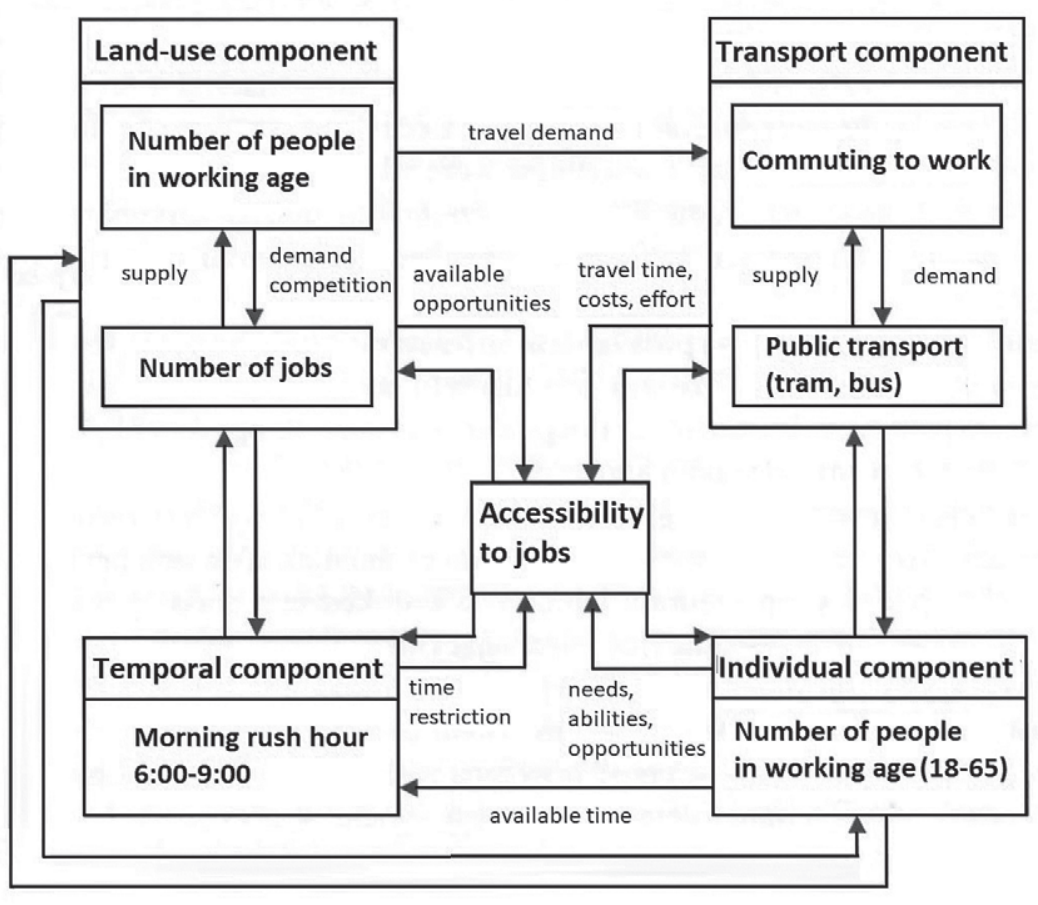

Figure 1. Relationship between components of accessibility Source: Geurs \& Ritsema van Eck (2001) and Geurs \& van Wee (2004).

\section{Data and case study}

General data used in the study includes the REGON database containing information on companies operating in Szczecin which declared in 2016 that they employ more than 10 employees. The REGON database includes all companies existing in the current year and those that were set up between 2008 and 2016. 
Moreover, information derived from the 2010 Comprehensive Traffic Analysis in Szczecin was used for the purposes of the study. This information allowed to assess the percentage of citizens commuting to work by collective transport in a particular age group. The 2010 CTA also provided information on freight performance of particular modes of transport what made it possible to calculate a share of commuters taking public transportation to work.

Commuting to work is a vital part of everyday journeys taken by people. According to the 2010 Comprehensive Traffic Analysis, 38\% of commuters in Szczecin use means of collective transport during the morning rush hours, i.e. 6:00-9:00 am. The same study showed that commuting to work is a significant motivation for approximately $65 \%$ households. Assuming that the study concerned people of working age (20-65 years) living in Szczecin, the problem of collective transport effectiveness during the rush hours directly affects 68 thousand of people.

The collective transportation model established for Szczecin complies with the timetable valid from March to June 2015. The primary source of data used in the analysis is the General Transit Feed Specification for the city of Szczecin. These data contain information about the location of stops, frequency of public transport service and directions of public transport transit lines. Roads and Transport Management (ZDiTM) in Szczecin provides the data in GTFS format. The data are ready for use in the ArgGIS 10.2 tool Network Analyst. An important source of data that were used in the analysis to identify deviations in the operation of public transport are information from a number of population divided into statistic perimeters (2011). These data are available to the public and have been downloaded from the geostatistical portal. Additional data sources are obtained by Open Street Map saved as shp format, which were used to generate connections between stops, as paths of pedestrian crossing to / from places where public transport does not reach (the average walking speed of 4.5 km / h; Farber et al. 2014; Ratajski 1989).

The study covers the area of the city of Szczecin, north-west Poland. The city area of $300 \mathrm{~km}^{2}$ has a population of about 400000 (Fig. 2). The public transport network consists of a radial tramway network and supplemented by a bus network, which connects most of the residential areas with the city centre. The night-time public transport is operated by 16 dedicated night-bus routes (Stępniak \& Goliszek 2017). 


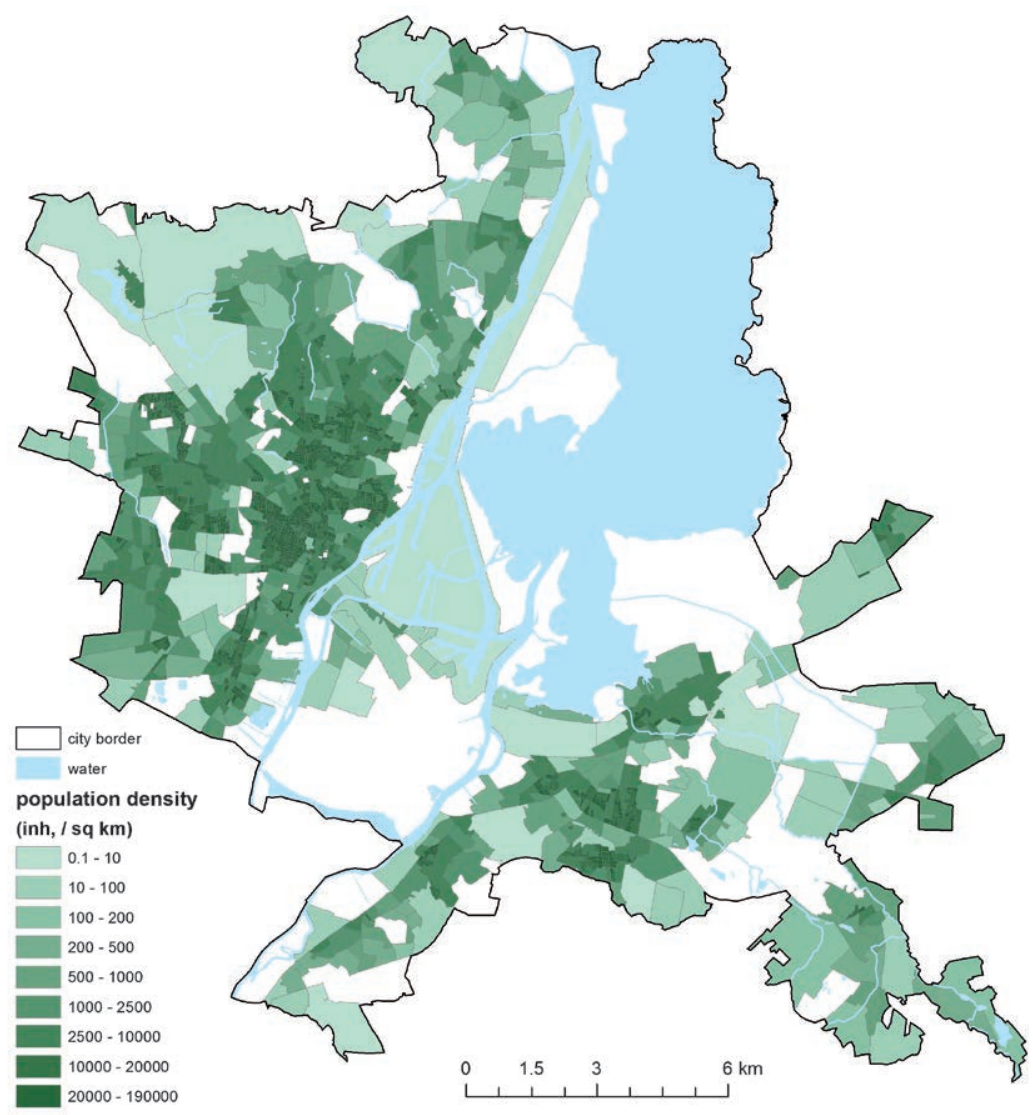

Figure 2. Population density in Szczecin (according to National Census 2011) Source: Stępnak \& Goliszek 2017.

\section{Methods}

The method used in the project is the cumulative accessibility measure (Wachs \& Kumagai 1973; Vickerman 1974), also called the isochrone-based accessibility measure. In the literature time accessibility is also referred to as daily accessibility - in units of time. When analysing commuting to work, an average travel time was taken under consideration yet no longer than 30 minutes. Such a period of time complies with the average travel time by public transport in Szczecin revealed by the 2010 CTA.

Time intervals at 1 minute intervals make it important to combine home-work that is wellcommunicated by public transport. The delay of collective transport, which operates according to a specific timetable, adds waiting time to the time of transit and another collective transport or, if it is better, another trip option or pedestrian crossing is selected. To be able to calculate the travel time of each use public transport to public transport travel time added a transition time to stop (Salonen \& Toivonen 2013). This is well illustrated by the diagram of work Solonen M. and T. Toivonen (2013), in which imaged the path of travel from one point to another using public transport (Fig. 3). 
Previous studies apply a wide range of walking speeds, starting from 3.2 up to $5.4 \mathrm{~km} / \mathrm{h}$, on this basis walking connections between exit and entry points have an average pedestrian speed of $4.5 \mathrm{~km} / \mathrm{h}$.

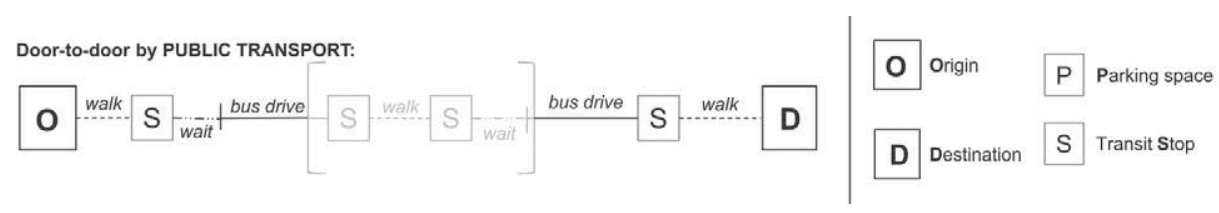

Figure 3. Travel scheme using by public transport Source: Salonen \& Toivonen 2013.

\section{Jobs in Szczecin}

There are much more jobs in Lewobrzeże (western bank of the city) than in Prawobrzeże (eastern bank of the city) of Szczecin. In Lewobrzeże there are $86,5 \%$ of all jobs offered in the city while in Lewobrzeże only $13,5 \%$ of them. When comparing the number of jobs with the population density it becomes clear that approximately 25 thousand of people of working age are forced to commute to Lewobrzeże, assuming that all the citizens work near their place of residence (Fig. 4). Such a number of people, excluding those who work outside the city (Fig. 5 - left), have to travel along the national road No. 10 (by bus or car) or take a fast tram.

Moreover, it is necessary to mention people working in Szczecin who do not live in the city itself and have to commute to work from other municipalities. In the study the maximum commuting distance of 100 kilometres was taken under consideration. The author claims that such a distance is reasonable in the context of everyday commuting to work. The map (on the left) shows the number of commuting trips to Szczecin in a form of a ribbon while the cartogram presents the percentage of people of working age in the neighbouring municipalities. The map on the right presents differences in commuting to and from Szczecin (Fig. 5). 


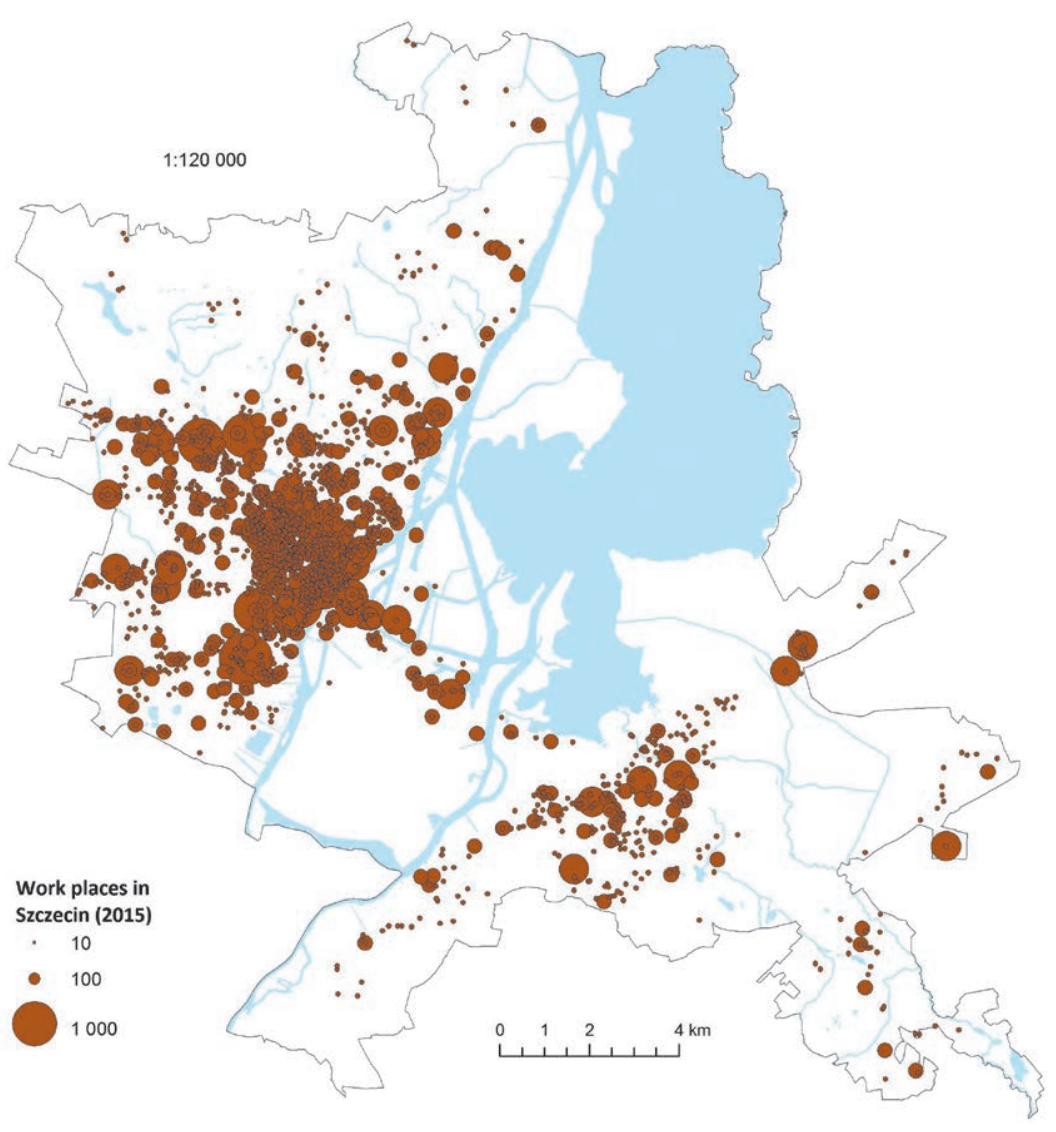

Figure 4. Distribution and size of workplaces Source: Elaboration own based on REGON data 


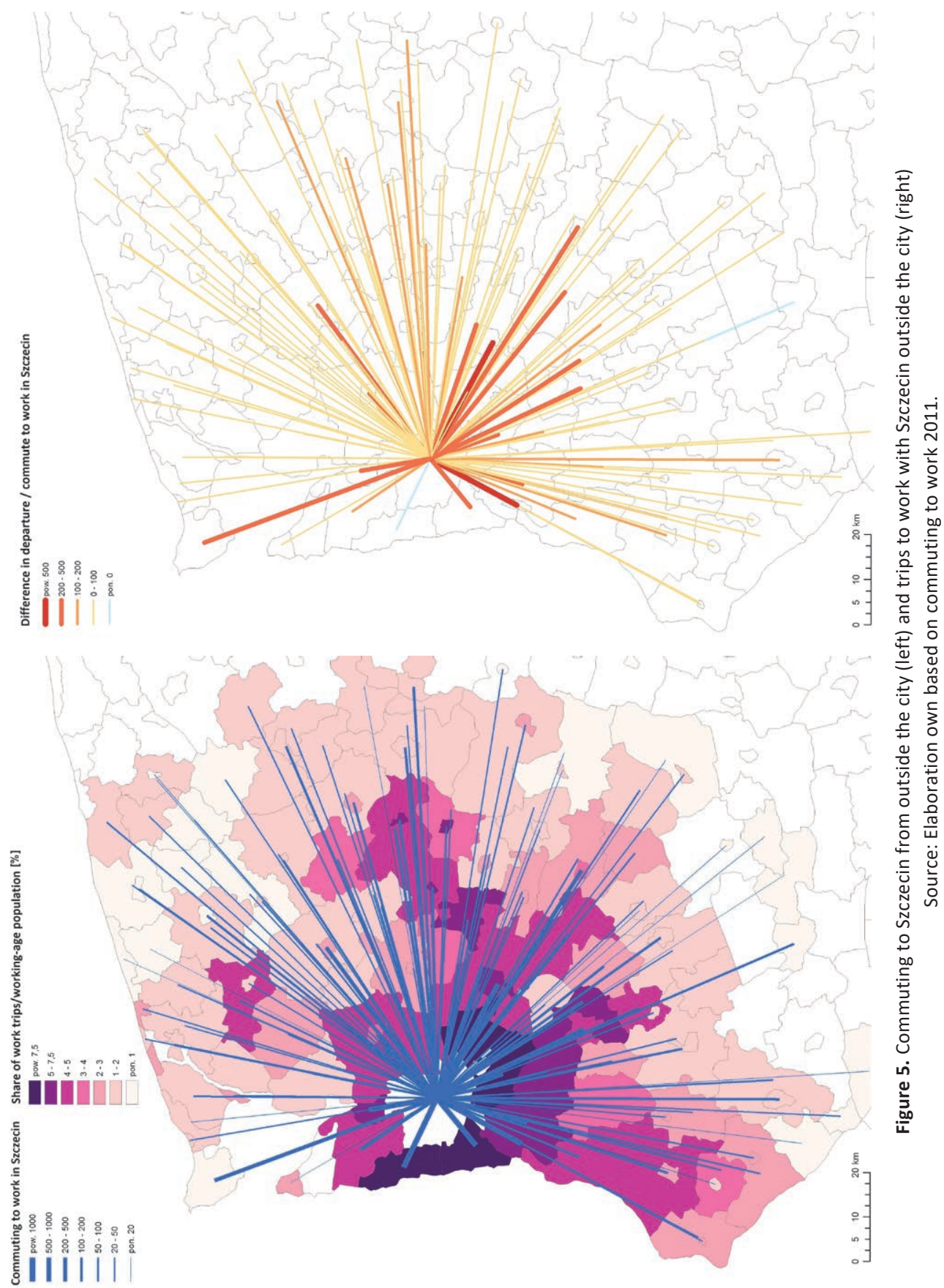




\section{Comprehensive traffic analysis and commute to work}

According to the 2010 Comprehensive Traffic Analysis, throughout the day the majority of commuters ( $42 \%$ ) use private cars, $19,62 \%$ of them travel by bus; $17,24 \%$ walk and $9,23 \%$ take the tram. Other means of transport are so rarely used that they are considered irrelevant in this study. The information on the means of transport used by the citizens of Szczecin was obtained by means of public opinion polls. Some of the citizens selected other means of transport than those indicated in the poll or they admitted to using multimodal transport e.g. buses and trams, private cars and collective transport.

During the morning rush hours, i.e. between 6:00 and 9:00, private car is also the most frequently used means of transport $(50,18 \%)$. It is worth mentioning that according to the respondents, during the morning rush hours the share of individual transport decreases from $50,18 \%$ to $38,41 \%$ and the percentage of people walking to work increases from $8,07 \%$ to more than $20 \%$. The shares of other means of transport do not change significantly during the morning rush hours. However, the results of the public opinion polls conducted under the 2010 CTA may be affected by the selection of particular hours during which the polls were conducted (Fig. 6).

On the basis of a public opinion poll conducted at the respondents' homes as well as with the use of other data (transport, social), flows of passenger traffic during the morning and afternoon rush hours were determined and described. For the purposes of this article a map was created with the use of the Vissum software (KBR 2010). The morning traffic flows for collective transport depict main directions of people's movements. The highest rate of traffic flow for collective transport, more than 1500 people per hour, was detected along the national road No. 10 leading from Lewobrzeże to Prawobrzeże. Another direction of high intensity is the section between Police and the city centre where the model rate of traffic flow ranged from 1000 to 1500 people per hour. However, there were small sections having the rate above 1500 . The software generated also a very high rate of traffic flow along the tram line in the city centre (Fig. 7).
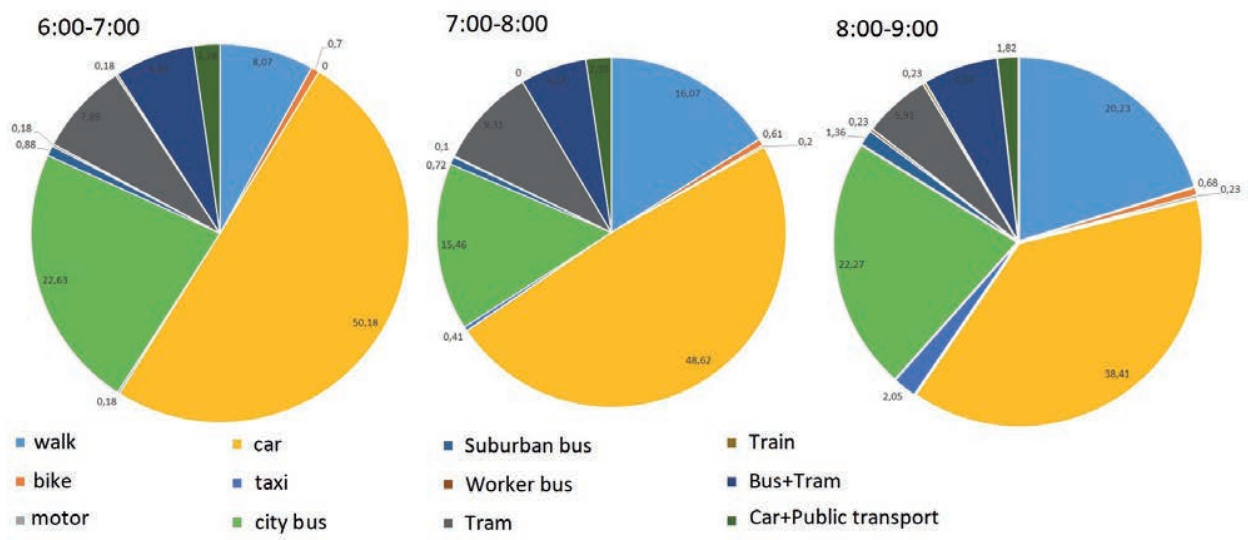

Figure 6. Results of comprehensive traffic research in Szczecin 2010 between 06:00 and 09:00 per hour Source: Comprehensive traffic research in Szczecin in 2010. 


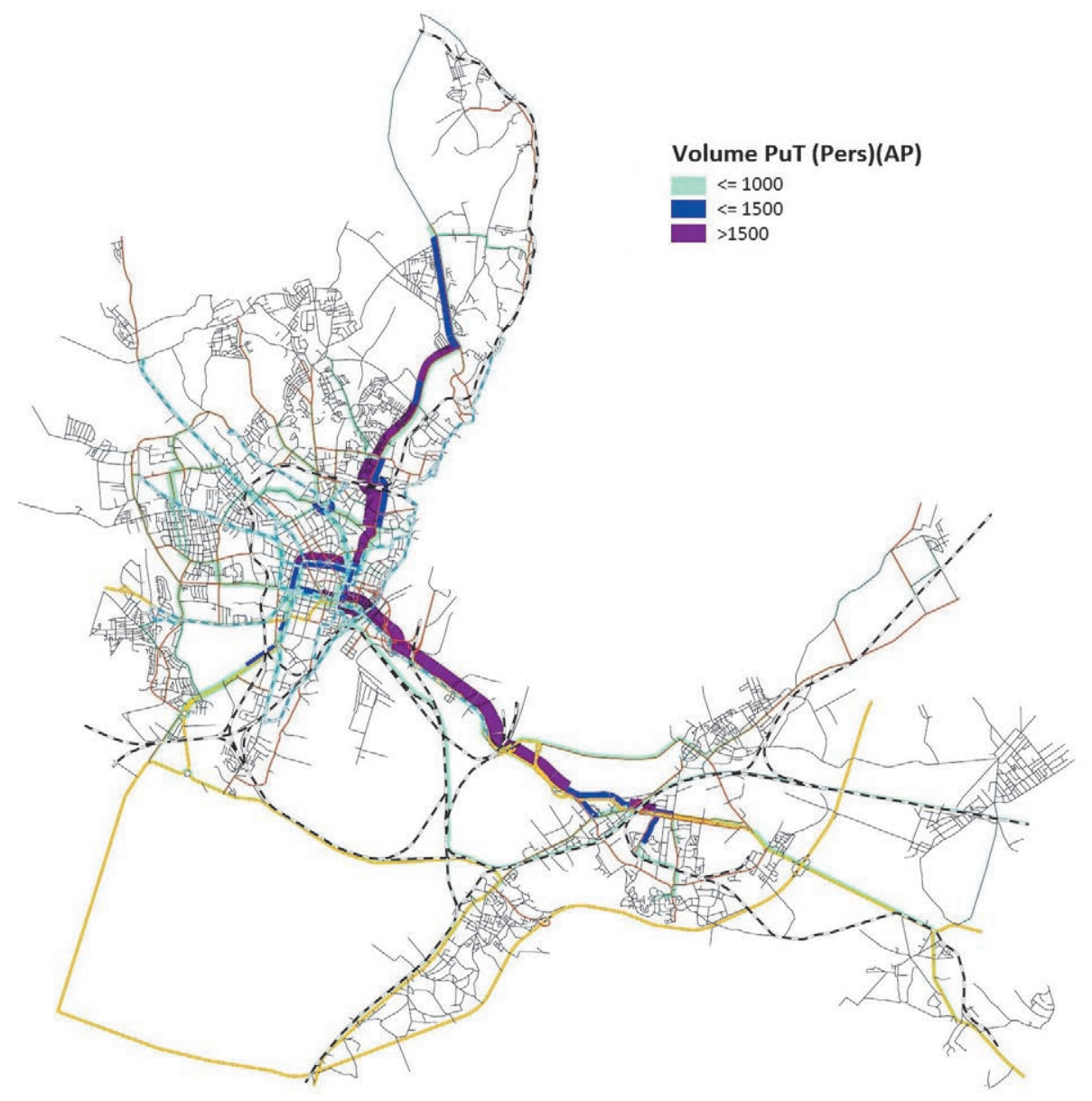

Figure 7. Traffic by public transport during the day

Source: Comprehensive Traffic Research in Szczecin in 2010.

\section{The results of analysis of commuting}

The results of simulation concerning accessibility of workplaces indicate that the best accessibility for collective transport during the morning rush hours is at 6:41. Nonetheless, it is not the only period of time with such high accessibility as there were some others with similar results. The worst morning accessibility, between 6:00 and 9:00, is at 8:50 (Fig. 7). The analysis has shown that the accessibility by collective transport varies over time (Goliszek \& Połom 2016). The possibility to commute to work by collective transport between the worst and the best time of departure is a $15 \%$ difference in workplace accessibility. The analysis has also provided some significant information on the morning rush hours. If an analysis of the morning rush hours includes collective transport, it should be carried out between 6:00 and 8:00 am. During this period of time the efficiency of commuting by collective transport is the highest. 
When analyzing the values of standard deviation for work travel times it becomes clear that the highest ones are between 6:00 and 7:00 am. Thus, the travel times oscillate around the average and consequently the accessibility is high. However, the values of standard deviation for the period between 7:00 and 9:00 am are higher and much more diversified what may be the result of irregular frequencies of public transport services (Fig. 8).

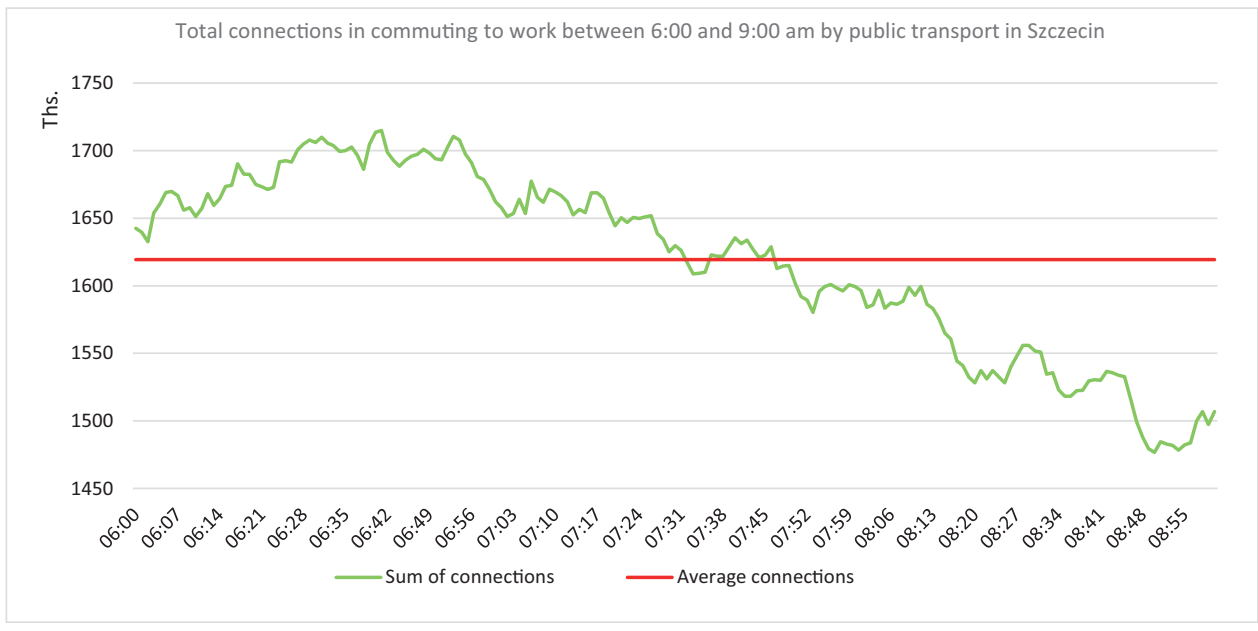

Figure 8. Sum of jobs in commuting between 6:00 and 9:00

Source: own elaboration.

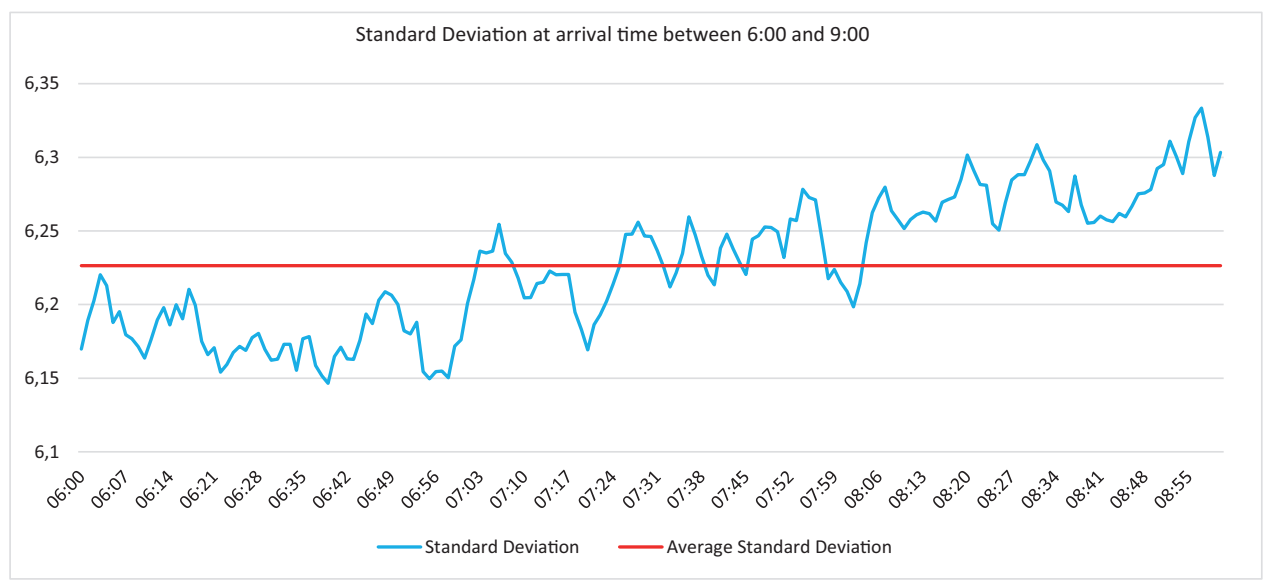

Figure 9. Standard Deviation at arrival time between 6:00 and 9:00

Source: own elaboration. 


\section{The results of a detailed analysis of maps}

The result of fluctuation in transport accessibility to workplaces (companies providing jobs) during the morning rush hours, which includes the best accessibility at 6:41 an the worst accessibilty at 8:50, has been presented as a percentage change (Fig. 8). The percentage change in the number of companies accessible by public transport within 30 minutes varies between two time profiles. The highest change in the accessibility is reported around the city centre where it has improved by more than $50 \%$. In the city centre the change in the accessibility is much lower. A decrease in commuting to work has been observed north of the city centre, in Prawobrzeże and in some relatively small areas within the city as shown in figure 9 . In areas where the highest increase in accessibility is observed, it is a result of irregular frequencies of collective transport services (Goliszek \& Połom 2016). Figure 8 also indicates areas having worse accessibility for the time profile established at 8:50. In most cases the decrease is caused by a gap in the timetable or it is affected by a frequency of a single bus or tram route. Such a situation takes place when no bus departures at 6:41 while at 8:50 leaves a vehicle connecting a given stop with the highest number of companies.

The analyses concerning workplaces and companies themselves have given similar results. The only feature differentiating those two analyses is the number of people employed in companies (Fig. 10). There are more companies employing more people in Lewobrzeże (western bank of the city). The analysis of the percentage difference in commuting to work (Fig. 11) has shown some areas having slightly better accessibility which are located near the city centre. The area located near Police is an interesting case study as an increase in commuting to companies and where there are few jobs have been recorded at the same time. Such a situation may take place when people living there have 30-minute accessibility to many companies at 6:41 but those companies do not provide many jobs. Having access to alternative means of transport (an additional bus) at 8:50 results in an increase in accessibility to the companies and a decrease in accessibility to the workplaces at the same time.

\section{Summary}

The analyses of commuting to work by public transport with the use of the General Transit Feed Specification data have provided some interesting results. Starting with determining the morning rush hours for collective transport, which are between 6:00 and 8:00 am, and finishing with designating places for optimal commuting to work when using the collective transportation system in Szczecin. The highest transport accessibility to companies and workplaces is in the city centre and in areas located near the already existing public transport infrastructure (the tram network in this case). Location, size and neighbourhood of companies are contributing factors in the context of their accessibility. Most workplaces in Szczecin are located in the city centre and in the areas located to the north and northwest of the centre. During the morning rush hours, at 8:50 (the hour with the worst accessibility) large areas located near the city centre have higher accessibility. Those areas have worse accessibility to public transport thus, higher frequencies of bus or tram services are not of great importance there and the good result may be affected by a single bus. Places with the traffic flow higher than 1500 people/hour during the morning rush hours (according to the 2010 Comprehensive Traffic Analysis) have worse accessibility at 8:50 and better accessibility measured at 6:41. Such results indicate that those places are easily accessible by the means of public transport 
at 6:51 while at 8:50 there is a gap in public transport services and that is why the difference in accessibility for the analysed time profiles is so huge.

\section{Conclusion}

This type of analysis can be useful for developers by picking new housing developments. Good accessibility to jobs is one of several determinants which are guided by developers of new housing at the location and their price. It is true that in the article Gadzińskiego and Radzimskiego (2015) there was a weak correlation between the fast tram and the price of housing. However, keep in mind that the authors of the article scrutinized with an investment tram, which was founded in 1997, when the economic situation in Poland was worse than today, and the housing market is not as developed as dizzily as it is now. 

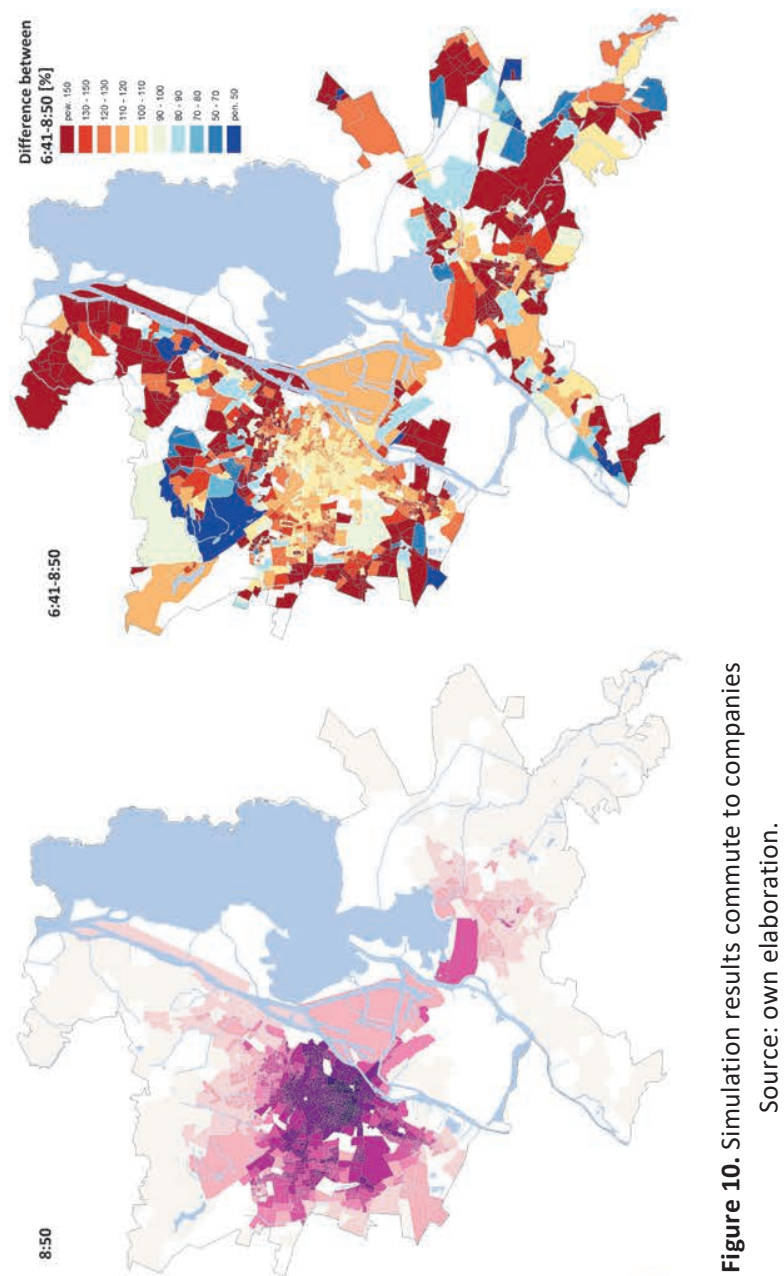

品

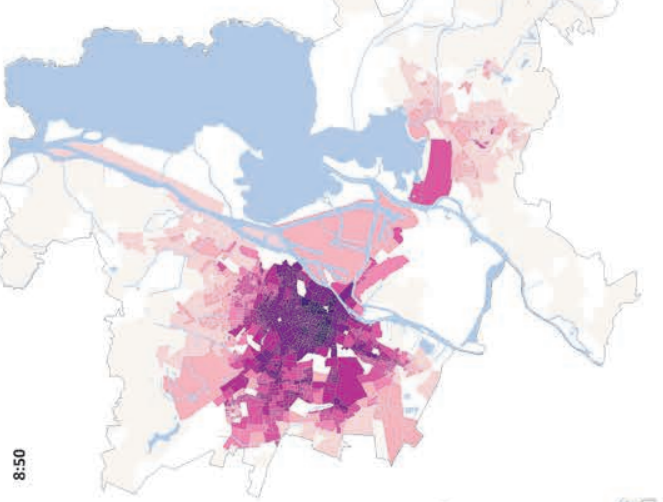

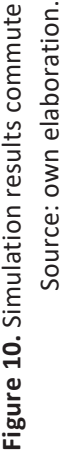

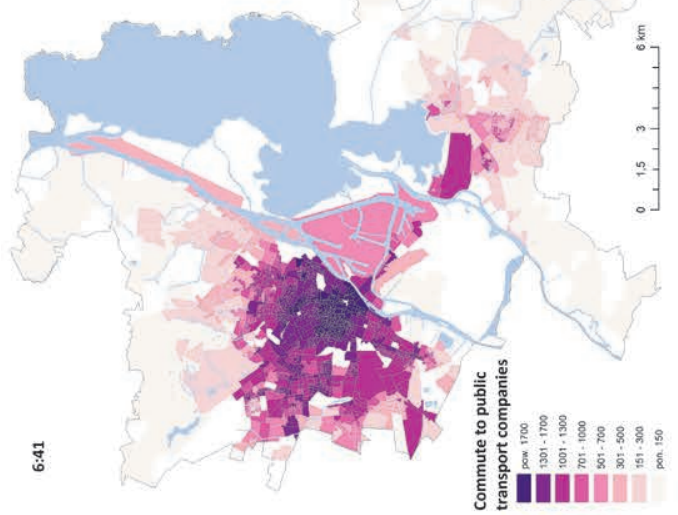

http://rcin.org.pl 

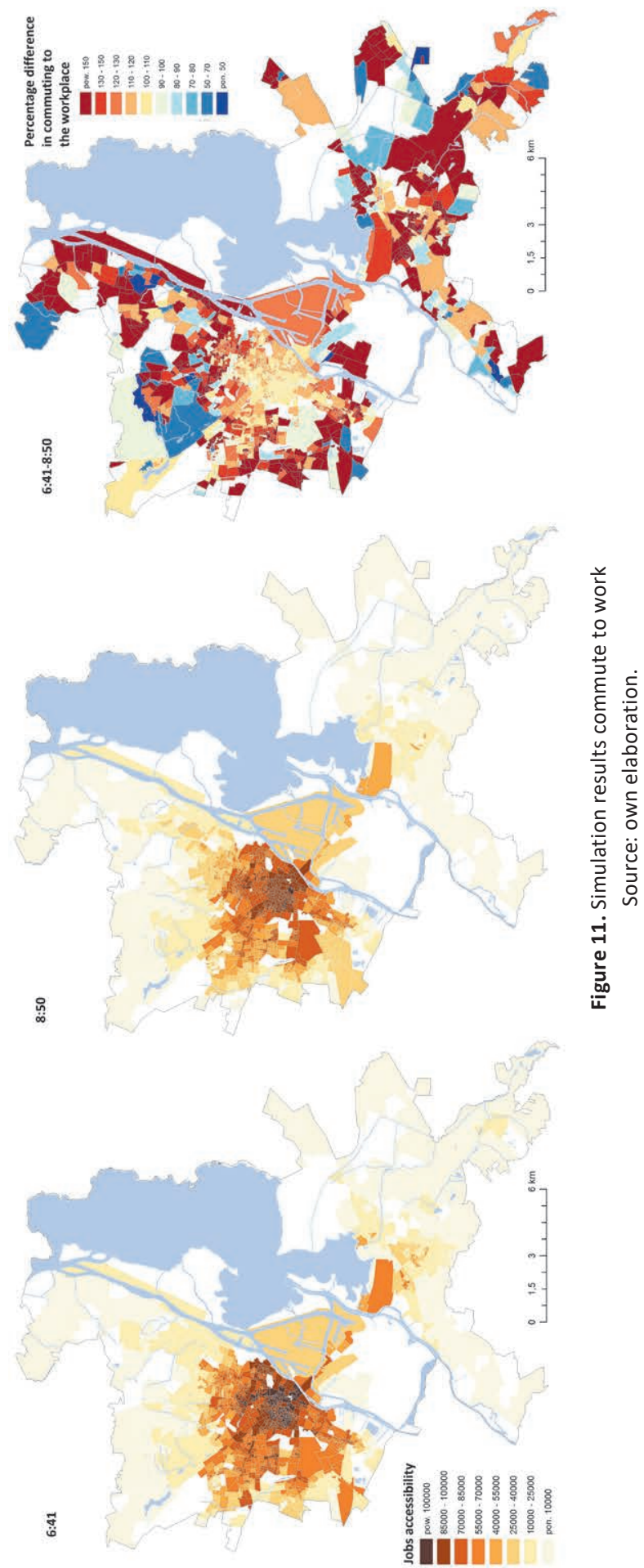


\section{References:}

Aguilera A., 2005. Growth in commuting distances in French polycentric metopolitan areas: Paris. Lyon and Marseille. Urban Studies, vol. 42 (9), pp. 1537-1547.

Åkerman J., Höjer M., 2006. Howmuch transport can the climate stand?-Sweden on a sustainable path in 2050. Energy Policy, vol. 34 (14), pp. 1944-1957.

Boussauw K., Derudder B., Witlox F., 2011. Measuring spatial separation process through the minimum commute: the case of Flanders. European Journal of Transport and Infrastructure Research, vol. 11 (1), pp. 42-60.

Cervero R., 2001. Efficient urbanisation: economic performance and the shape of theme tropolis. Urban Studies, vol. 38 (10), pp. 1651-1671.

Chowdhury T. A., Scott D. M., Kanaroglu P.S., 2013. Urban form and commuting efficiency: a comparative analysis across time and space. Urban Studies, vol. 50 (1), pp. 191-207.

Cropper M., Gordon P., 1991. Wasteful commuting: a re-examination. Journal of Urban Economics, vol. 29, pp. 2-13.

El-Geneidy A., Buliung R., Diab E., et al. 2015. Non-stop equity: Assessing daily intersections between transit accessibility and social disparity across the Greater Toronto and Hamilton Area (GTHA). Environ. Plan. B Plan. Des.

El-Geneidy A., Levinson D., Diab E., et al., 2016. The cost of equity : Assessing transit accessibility and social disparity using total travel cost. In 95th Annual Meeting of the Transportation Research Board. pp. 1-34. Washington D.C., USA.

Farber S., Morang M. Z., Widener M. J., 2014. Temporal variability in transit-based accessibility to supermarkets .Applied Geography, vol. 53, pp. 149-159.

Fransen K., Neutens T., Farber S., De Maeyer P., Deruyter G., Witlox F., 2015. Identifying public transport gaps using time-dependent accessibility levels. Journal of Transport Geography, vol. 48, pp. 176-187.

Gadziński J., Radzimski A., 2015. The first rapid tram line in Poland: How has it affected travel behaviours, housing choices and satisfaction, and apartment prices? Journal of Transport Geography, vol. 54, pp. 451-463.

Geurs K. T., De Montis A., Reggiani A., 2015. Recent advances and applications in accessibility modelling. Computer Environment Urban System, vol. 49, pp. 82-85.

Geurs K. T., Ritsema van Eck J. R., 2001. Accessibility measures: review and applications. RIVM report 408505 006, Bilthoven: National Institute of Public Health and the Environment.

Geurs K. T., van Wee B., 2004. Accessibility evaluation of land-use and transport strategies: review and research directions. Journal of Transport Geography, vol. 12, pp. 127-140.

Giuliano G., Small K., 1993. Is the journey to work explained by urban structure? Urban Studies, vol. 30 (9), pp. 1485-1500.

Givoni M., Banister D., 2013. Moving Towards Low Carbon Mobility. Cheltenham: Edward Elgar Publishing Limited.

Goliszek S., Połom M., 2016. The use of general transit feed specification (GTFS) application to identify deviations in the operation of public transport at morning rush hour on the example of Szczecin. Europa XXI, vol. 31, pp. 51-60.

Hadas Y., 2013. Assessing public transport systems connectivity based on Google Transit data. Journal of Transport Geography, vol. 33, pp. 105-116. 
Hamilton B.W., 1982. Wasteful commuting. Journal of Political Economy, vol. 90 (5), pp. 1035-1053.

Kim S., 1995. Excess commuting for two-worker households in the Los Angeles metropolitan areas. Journal of Urban Economics, vol. 38 (2), pp. 166-182.

Kompleksowe Badania Ruchu w Szczecinie w 2010 roku.

Lau C.Y., 2011. Spatial mismatch and the affordability of public transport for the poor in Singapore's new towns. Cities, vol. 28 (3), pp. 230-237.

Loo B., Chow A., 2011. Jobs-housing balance in an era of population decentralization: an analytical framework and a case study. Journal of Transport Geography, vol. 19 (4), pp. 552-562.

Lucas K., 2011. Making the connections between transport disadvantage and the social exclusion of low income populations in the Tshwane Region of South Africa. Journal of Transport Geography, vol. 19 (6), pp. 1320-1334.

Małecki K., Iwan S., Kijewska K., 2014. Influence of Intelligent Transportation Systems on Reduction of sthe Environmental Negative Impact of Urban Freight Transport Based on Szczecin Example. Procedia-Social and Behavioral Sciences. vol. 151, pp. 215-229.

Manning A., 2003. The real thin theory: monopsony in modern labour markets. Labour Economics, vol. 10 (2), pp. 105-131.

Modarres A., 2013. Commuting and energy consumption: toward an equitable transportation policy. Journal of Transport Geography. vol. 33, pp. 240-249.

Naudé W., 2008. Is there a spatial mismatch in South Africa's metropolitan labour market? Cities, vol. 25 (2), pp. 268-276.

Niedzielski M. A., 2006. A spatially disaggregated approach to commuting efficiency. Urban Studies, vol. 43 (13), pp. 2485-2502.

Niedzielski M. A., Horner M.W., Xiao N., 2013. Analyzing scale independence in jobs-housing and commute efficiency metrics. Transportation Research Part A: Policy and Practice.

Novaco R.W., Gonzalez O.I., 2009. Commuting and well-being [in:] Amichai-Hamburger Y. (ed.), Technology and Wellbeing. Cambridge: Cambridge University Press, pp. 174-205.

O'Kelly M. E., Lee W., 2005. Disaggregate journey-to-work data: implications for excess commuting and jobs-housing balance. Environment and Planning A, vol. 37 (12), pp. 2233-2252.

Poelman H., Dijkstra L., 2015 Measuring access to public transport in European cities. Regional and Urban Policy. 17 pp.

Punpuing S., 1993. Correlates of commuting patterns: a case-study of Bangkok, Thailand. Urban Studies, vol. 30 (3), pp. 527-545.

Salonen M., Toivonen T., 2013. Modelling travel time in urban networks: comparable measures for private car and public transport. Journal of Transport Geography, vol. 31, pp. 143-153.

Shearmur R., 2006. Travel from home: an economic geography of commuting distances in Montreal. Urban Geography, vol. 27 (4), pp. 330-359.

Shirgaokar M., 2014. Employment centers and travel behavior: exploring the work commute of Mumbai's rapidly motorizing middle class. Journal of Transport Geography, vol. 41, pp. 249-258.

Stępniak M., Goliszek S., 2017. Spatio-temporal variation of accessibility by public transport - the equity perspective [in:] I. Ivan, A. Singleton. J. Horák, T. Inspektor, The rise of big spatial data. Cham: Springer International Publishing, pp. 241-261.

Tao S., Rohde D., Corcoran J., 2014. Examining the spatial-temporal dynamics of bus passenger travel behaviour using smart card data and the flow-comap. Journal of Transport Geography, vol. 41, pp. 21-36. 
Vickerman R. W., 1974, Accessibility, attraction and potential: A review of some concepts and their use in determining mobility. Environment and Planning A, vol. 6, pp. 675-691.

Wachs M., Kumagai T., 1973, Physical accessibility as a social indicator. Socioeconomic Planning Science, vol. 7, pp. 327-456.

Wang C.-H., Chen N., 2015. A GIS-based spatial statistical approach to modeling job accessibility by transportation mode: case study of Columbus, Ohio. Journal of Transport Geography. vol. 45, pp. 1-11.

White M. J., 1988. Urban commuting journeys are not 'wasteful'. Journal of Political Economy. vol. 96 (5), pp. 1097-1110.

Widener M. J., Farber S., Neutens T., Horner, M., 2015. Spatiotemporal accessibility to supermarkets using public transit: an interaction potential approach in Cincinnati. Ohio. Journal of Transport Geography. vol. 42, pp. 72-83.

Yang J., 2008. Policy implications of excess commuting: examining the impacts of changes in US metropolitan spatial structure. Urban Studies, vol. 45 (2), pp. 391- 405.

Yongling, Y., Guonan, Z., 2009. Empirical analysis of spatial mismatch of living-working: based on a field survey in downtown Beijing. International Journal of Urban Sciences, vol. 13 (1), pp. 1-17.

Data:

Database company REGON acquisition 5.2016

General Transit Feed Specification (GTFS) https://developers.google.com/transit/gtfs/reference/ General Transit Feed Specification in Szczecin http://www.zditm.szczecin.pl/rozklady/GTFS/latest/ Kompleksowe Badania Ruchu w Szczecinie 2010 - Comprehensive Traffic Research in Szczecin 2010 http://bip.um.szczecin.pl/chapter_11124.asp?soid=DFD7E3651BF74AD0824410CF5F8E4944

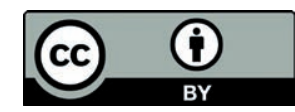

